\title{
EDITORIAL
}

\section{Liderazgo como motor de desarrollo}

Es una gran satisfacción presentarles, otro número de la revista científica Ciencia Amazónica (Iquitos) con el tema "El liderazgo como motor de desarrollo". Este número está lleno de grandes expectativas, ya que nuestra visión es ampliar la cobertura a publicaciones de artículos sobre análisis, reflexiones y principalmente nuevos conceptos y teorías sobre el liderazgo, la gestión y el emprendimiento. Temas ampliamente tratados en los últimos 30 años en investigaciones científicas.

Al hablar sobre los estilos y teorías de liderazgo, encontramos diferentes miradas de investigadores a nivel mundial, algunos de ellos han logrado un amplio desarrollo del tema y han generado corrientes de investigación válidamente posicionadas en el ámbito científico mundial. Algunos de estos referentes del liderazgo son Burns, Bass, Avolio, Gardner, Conger, Kanungo, Jung, Yulk, entre otros.

El estudio del liderazgo, reconoce efectos sobre variables como el grado de satisfacción, motivación y desempeño (rendimiento), de los colaboradores, los que a su vez afectan la eficacia de las organizaciones.

El liderazgo representa también un rasgo importante que define las capacidades emprendedoras de los individuos. Por su parte, la generación de procesos emprendedores, es un atributo que fortalece el desarrollo de las organizaciones. Autores relevantes, como Chumpeter y el mismo Draker han posicionado hasta nuestros días, el emprendimiento como eje del desarrollo y al liderazgo como Motor de cambio organizacional para el desarrollo.

Un alto rendimiento de las empresas, facilita su crecimiento y su rentabilidad, la que a su vez puede generar empleo y contribuir al crecimiento económico de la región y país en que dicha organización se sitúa. Las Organizaciones en general (públicas y privadas), son una palanca de desarrollo importante para los países, por lo cual al estudiar las experiencias exitosas, se está buscando como apoyar el desarrollo local y nacional.

Importantes estudios a nivel mundial, como el GEM (Global Entrepreunerchip Monitor), se preocupan de la importancia de las habilidades emprendedoras, como eje del desarrollo de las organizaciones y se estudian las variables personales, que influyen en las habilidades para liderar organizaciones exitosas. 
Es en este contexto, es que en los últimos años se han estudiado realidades en variadas organizaciones latinoamericanas (publicas, privadas, productivas, de servicios, con y sin fines de lucro), para determinar los estilos de liderazgo ejercidos en éstas.

El hallazgo que se rescata como un aporte de estos trabajos, es que en varios de los estudios desarrollados en organizaciones exitosas, en distintos rubros y países latinoamericanos, se ha encontrado que gerentes y altos directivos, se comportan como líderes del tipo transformacional de manera predominante.

El Líder Transformacional es un agente de cambio inspirador, que promueve entre sus seguidores una forma diferente de ver su trabajo, al inducirlos a la ejecución de tareas, no en función de una recompensa o un intercambio, sino en función de su realización como ser humano dentro la organización. Un líder transformacional logra en sus seguidores crear un sentido de pertenencia con la organización, ambientes de confianza, lazos afectivos, identidad organizacional y un alto grado de compromiso con el logro de las metas organizacionales. Es coherente entonces, que este tipo de liderazgo sea el que predomine en las organizaciones exitosas, que a su vez aportan al desarrollo local y al de las naciones.

Este importante desafío para la revista, entregará una mirada a la gestión organizacional, desde el liderazgo y el emprendimiento, como elementos claves para el desarrollo endógeno de las organizaciones y los países latinoamericanos.

\author{
Alberto Alejandro Martínez Quezada \\ Profesor Asociado \\ Decano Facultad de Ingeniería y Arquitectura \\ Universidad Arturo Prat, Chile \\ Equipo Editorial
}

